\title{
LA INDUMENTARIA DIVINA COMO VEHÍCULO DE PROPAGANDA POLÍTICA Y SOCIAL. REFLEXIONES DESDE ARCADIA* \\ THE CLOTHING OF THE GODS AS A VEHICLE OF POLITICAL AND SOCIAL PROPAGANDA. SOME REFLECTIONS FROM ARKADIA
}

\author{
VASILIS TSIOLIS \\ Universidad de CAstilla-La Mancha \\ TSIOLIS@UCLM.ES
}

\section{RESUMEN}

La indumentaria divina, ampliamente tratada desde múltiples puntos de vista en los estudios de la Antigüedad, también se presta a análisis que ponen de manifiesto connotaciones ideológicas, de tipo social o político, a menudo propagandístico, conscientemente reflejadas bien en las propias prendas reales, bien en las obras artísticas que las representan o en elaboradas narrativas. En la presente contribución me propongo llevar a cabo una aproximación a la cuestión desde esta perspectiva "política" e ideológica, discutiendo dos casos de vestidos destinados a sendas diosas arcadias: el vestido de la diosa Despoina, parcialmente

\begin{abstract}
The clothing of the gods, widely treated from different points of view in the ancient studies, can be analyzed in terms of its ideological, social or political connotations. Such connotations are often propagandistic and have been consciously reflected in the real attire itself or in garments represented on artistic works and elaborate narratives. In this paper I am proposing to approach the issue from a "political" and ideological perspective, discussing two cases of dresses of arkadian goddesses: the garment of the goddess Despoina, as it can be seen in a fragment of the acrolithic cultic group of her sanctuary at Lycosoura, on the one hand, and the peplos
\end{abstract}

${ }^{*}$ Deseo expresar mi agradecimiento a los evaluadores anónimos, así como a los editores de ARYS, que, con sus comentarios, han contribuido a mejorar algunos aspectos de la presente aportación. 
conocido por un fragmento marmóreo del grupo escultórico de culto del santuario de Licosura, por un lado, y el peplos enviado a Atenea Alea de Tegea por parte de una mujer residente en Chipre, llamada Laodice, por otro. Teniendo en cuenta el extraordinario bagaje religioso de la región, junto con su capacidad de aglutinar elementos de culto innovadores (pero también su versatilidad religiosa ante los imperativos políticos y sociales, así como su papel protagonista en el Peloponeso durante la época helenística, especialmente en el marco de la Liga aquea), estos dos casos sirven para profundizar en lo que se percibe detrás de las telas, es decir el mensaje que las prendas, por sus características, pretenden transmitir. El análisis nos conduce a vislumbrar la posible exaltación triunfalista y propagandística de alguna realidad no estrictamente religiosa, quizás una victoria militar de la Liga aquea, en el caso de Licosura y un acto posiblemente adscribible a un contexto de diplomacia internacional, orientada a crear redes de parentesco entre Chipre y Tegea, en un intento de potenciar las relaciones entre las partes para beneficio mutuo. offered to Athena Alea at Tegea by Laodice, a woman resident in Cyprus, on the other. Bearing in mind the extraordinary religious background of Arkadia, along with its ability to bring together innovative elements of worship (but also its religious versatility in changing political and social contexts, as well as the leading role of this region in the Peloponnese during the Hellenistic period, especially as part of the Achaean League), the two cases chosen serve to the present study as a platform to deepen what is the message that garments, by their characteristics, intend to convey. The analysis leads us to glimpse the possible triumphalist and propagandistic exaltation of some reality not strictly religious, perhaps a military victory of the Achaean League, in the case of Lycosoura and an act possibly to place in an international diplomacy context, aimed at creating networks of kinship between Cyprus and Tegea, in an attempt to enhance relations between the parties for mutual benefit.

\section{PAlabras Clave}

Agapenor, Chipre, indumentaria divina, manto de Despoina, Licosura, peplos de Laodice, Tegea

\section{KEYWORDS}

Agapenor, clothing of the gods, Cyprus, garment of Despoina, Lycosoura, peplos of Laodice, Tegea

Fecha de recepción: 03/06/2019

Fecha de aceptación: 22/09/2019 
LA CUESTIÓN DE LA INDUMENTARIA DIVINA es ampliamente tratada en numerosos y muy diversos contextos de la historia cultural, religiosa y social de la Antigüedad, generando una extensa problemática abierta al debate. En este dilatado marco analítico e interpretativo, las vestimentas empleadas en la esfera religiosa (fueran éstas bien las endosadas por personas reales durante las funciones litúrgicas o rituales, bien las que portaban las estatuas de culto o las que adornaban a los personajes divinos en los relatos mitológicos y literarios, así como en el arte pictórico y escultórico) se prestan también a lecturas de su perfil menos hierático y a la investigación de la ideología sociopolítica que encierran, más allá de sus valores histórico-religiosos o histórico-artísticos. Desde esta perspectiva concreta, la interpretación de la fenomenología de la indumentaria religiosa ha de partir del estudio de episodios históricos reconocibles, que permiten otorgar a estas vestimentas matices alusivos a una más o menos sutil propaganda social o política.

En la presente contribución, me propongo llevar a cabo una aproximación a la cuestión a través del análisis de dos casos de indumentaria de estatuas de divinidades, documentadas en la Arcadia helenística. El contexto cultural y religioso arcadio de época helenística se presta al tipo de estudio propuesto, habida cuenta de su extraordinaria riqueza religiosa, tanto en lo que concierne a sus cultos y tradiciones ancestrales, que perviven fosilizados o resucitan reinventados, como en lo referente a la versatilidad de esta región a la hora de añadir a su bagaje religioso elementos innovadores, dictados más por imperativos políticos, administrativos o sociales, que por estímulos meramente devocionales. Asimismo, algunas ciudades de Arcadia asumen un papel protagonista durante la época helenística, especialmente en el marco de la Liga aquea, cuyo control político se focaliza en cierta medida, aunque de manera intermitente, en esta región.

Los dos casos de indumentaria elegidos para el presente estudio atañen a sendas estatuas de culto: por un lado, el vestido de Despoina, diosa de Licosura, conocido a través de fragmentos del grupo escultórico cultual de su santuario, y, por otro lado, el peplos para Atenea Alea, enviado a Tegea desde Chipre, por parte de una mujer llamada Laodice. Ambas prendas han repetidamente llamado la atención de la investigación moderna, ya que bien su contexto histórico e histórico-religioso, bien - en el primer caso - la original iconografía de su registro ornamental, plantean una serie de cuestiones todavía abiertas. 
La indumentaria de Despoina, examinada bajo el enfoque de su posible vinculación con una determinada línea de propaganda política y social, invita a tratar de esclarecer algunos parámetros de su iconografía. Contextualizando brevemente la pieza escultórica es necesario recordar que el (supuestamente) vetusto santuario de Despoina en Licosura, ${ }^{1}$ en la Arcadia suroccidental, ya respetado y probablemente potenciado en la época de fundación de Megalópolis (poco después del 370 a.C.), se revitaliza de manera extraordinaria en algún momento de época helenística, entre finales del siglo III y primeras décadas del siglo II a.C. En estos momentos Licosura ostenta el estatuto de polis autónoma, aunque está vinculada de alguna manera a la vecina Megalópolis. El santuario es objeto de una extensa intervención arquitectónica, que afecta sin duda al templo principal, ${ }^{2}$ en el que se cobija el grupo escultórico de culto, obra de Damofón de Mesene. La actividad de Damofón en Licosura está documentada, además que por el testimonio de Pausanias, tanto por vía epigráfica, en especial gracias a un decreto de proxenía hallado en Mesene y emitido por la polis de Licosura a favor del escultor, como a través del hallazgo de varios fragmentos de la composición escultórica original. Estos fragmentos, junto con la descripción pausaniana y la imagen del reverso de una moneda severiana de Iulia Domna han permitido reconstruir parcialmente el grupo cultual damofonteo: Despoina, la joven diosa titular del santuario, aparece solemnemente vestida y sentada a la izquierda de su madre Deméter con la que comparte trono. Su mano derecha descansa sobre una cista apoyada en su muslo derecho, mientras que el brazo izquierdo aparece semilevantado y flexionado, sujetando con la mano un cetro y el extremo de su indumentaria, que cae formando pliegues. Deméter, por su lado, vestida con túnica, también está sentada y apoya su brazo izquierdo sobre el hombro de la hija, mientras que con la mano opuesta agarra una antorcha. Junto al trono, a la izquierda de Deméter y realizada en menor tamaño, aparece, de pie, Artemis, con carcaj en su espalda, antorcha en su mano derecha, dos serpientes enrollados en su brazo izquierdo y con un perro junto a sus pies. En el extremo opuesto del trono, al lado de Despoina, aparece Ánito, titán encargado de criar a la diosa, también esculpido en tamaño menor, de pie y armado con lanza. Pausanias menciona, asimismo, figuras de Coríbantes y Curetes adornando la basa del grupo escultórico, sin entretenerse en describirlas ni a

1. Paus., VIII 37, 1-12.

2. De entre los estudios más recientes, Billot, 2008, propone una datación del templo entre finales del siglo IV a.C. y mediados del siguiente, pensando en una construcción gradual, realizada en diferentes etapas; esta cronología difícilmente se ajusta con la época de actividad del escultor Damofón, actualmente fijada entre finales del siglo III a.C. y mediados del siguiente: Themelis, 1993; cf. Grandjean y Nicolet-Pierre, 2008; Jost, 2008a; Palamidis, 2018. 
explicarlas. De estas figuras no se encontraron restos; en cambio se han conservado en buen estado cuatro figuras de Tritonisas, resaltando un extraño protagonismo del elemento marino para un santuario del interior montañoso de la Arcadia. Esta presencia de seres marinos es interpretable, con toda probabilidad, como alusión a los dominios del padre de Despoina, Poseidón (fig. 1). ${ }^{3}$

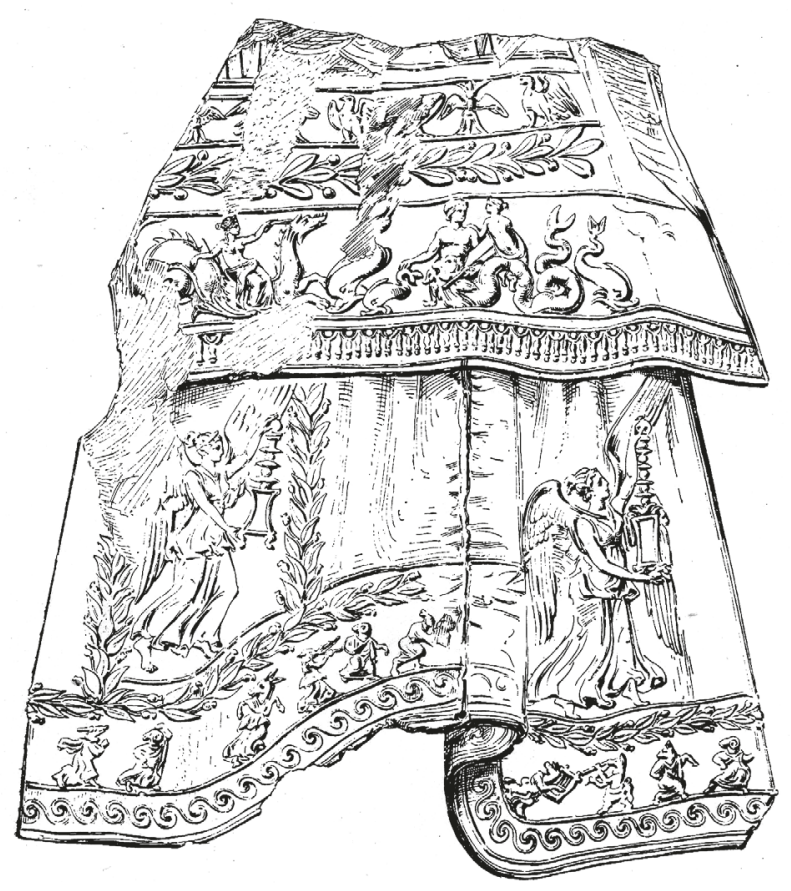

Fig.1. Dibujo del principal fragmento escultórico del vestido de Despoina (según Dickins, 1906-1907, tav. 14.)

De entre los fragmentos del grupo escultórico conservados destaca el que corresponde a la parte del ropaje que Despoina sujetaba junto con el cetro, según las

3. Poseidón es indicado como padre de Despoina en Paus., VIII 37, 10. Sobre otras tradiciones arcadias que asocian a Poseidón con Deméter, de cuya unión habría (o podría haber) nacido Despoina, véase, en última instancia Palamidis, 2018, pp. 137-139. 
reconstrucciones más aceptadas (fragmento 1737 del Museo Arqueológico Nacional de Atenas). Este fragmento del vestido de la diosa resulta ser muy original y prácticamente sin parangón entre la indumentaria conocida a través de piezas escultóricas griegas. La pieza conservada se presenta aparentemente compuesta por dos paños parcialmente superpuestos, cubriendo el más corto (himation), la parte superior del elemento más largo, la túnica. ${ }^{4}$ Sus características tipológicas parecen remitir a telas elaboradas con finísima técnica de bordado, más que a prendas tejidas, al caracterizarse por una profusa decoración realizada en bajorrelieve y distribuida en varias franjas paralelas de desigual anchura sobre la superficie de ambas porciones de tejido. En la superior (himation) se conserva una fila de águilas alternadas con rayos alados (alusión, a primera vista, a Zeus, posiblemente el Lykaios del vecino Monte Liceo), seguido por una banda decorada con una rama de olivo (o laurel) y, a continuación, por una banda más ancha, decorada con un movido thiasos marino (Nereida sobre Tritón dirigiéndose de derecha a izquierda, rodeados de delfines, y Victoria marina montando a un hipocampo, con dirección opuesta). Termina esta porción superior del vestido rematada con una elaborada flocadura. En la parte correspondiente a la túnica, entre pliegues, predomina un amplio friso con dos grandes figuras de Nikai aladas, portadoras de sendos objetos interpretados habitualmente como thymiaterial incensarios, que, sin embargo, cabría precisar como altaria/bomiskoi. ${ }^{5}$ Formando el dobladillo y separada por ramas de mirto (que, puntualmente, invaden también el friso de las Nikai desarrollándose en vertical), corre una banda más estrecha decorada con una animadísima fila de figuras en miniatura, con cabezas de animales, cuerpos

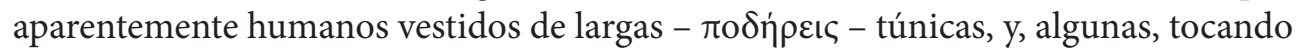
instrumentos musicales. Las figuras, de raza, sexo y edad indefinidos, están representadas en actitud de realizar - sin tocarse entre sí - una frenética danza-carrera (con

4. En la bibliografía anglófona ha prevalecido la palabra "veil" (velo) en la interpretación del fragmento, a partir de G. Dickins, que basaba en la idea de un velo recubriendo la cabeza de Despoina su reconstrucción del grupo escultórico (Dickins, 1906-1907, pp. 373-374. Actualmente existe la tendencia de emplear palabras más genéricas, tales como "garment" (prenda, vestido). Términos como "velo", "draperie", "manto" o peplos, se suelen utilizar en publicaciones en otros idiomas europeos. De entre los estudios más recientes destaca el análisis de Y. Morizot, que se manifiesta contraria a la interpretación de la pieza como velo, avanzada por de G. Dickins, reconociendo, en cambio, dos prendas, himation y túnica (Morizot, 2008, pp. 203-207). No parece probable que se trate de dos partes de una misma pieza redoblada sobre si misma.

5. Incensarios: véase, e.g., Jost, 2003, p. 156; Morizot, 2008, p. 203. Sobre la eventual interpretación de los objetos portados por las Nikai como altaria, véase infra, nota 14 . 
tintes rituales y, quizás, orgiásticos). ${ }^{6}$ Como es de esperar, el fragmento escultórico del vestido de Despoina ha suscitado un enorme interés entre los investigadores, que le han dedicado varios trabajos, convirtiéndolo en uno de los referentes más destacados en los estudios especializados. La pieza ha sido estudiada ampliamente desde el punto de vista técnico-textil y, naturalmente, iconográfico, centrándose sobre todo en la interpretación del friso con las figuras miniaturísticas danzantes. Las aproximaciones se han realizado a menudo en clave ritual-religiosa y exegética, ${ }^{7}$ prestando, en cambio, menor atención a eventuales aspectos de ideología política, más allá de aquella social, o cultural-religiosa, que podría encerrar la iconografía del ornato de la vestimenta de la diosa.

Que dichos aspectos pudieron haberse quedado reflejados en la representación escultórica no debería resultar extraño, si se tiene en cuenta la frecuencia con la que los griegos manifestaban sus posiciones ideológicas en sus construcciones sagradas y hasta en las propias estatuas de culto. En ese sentido, cabría esperar que las eventuales motivaciones político-ideológicas, que pudieron haber acompañado la promoción del santuario, hubiesen dejado su huella en las expresiones artísticas, por lo que sería conveniente un enfoque del vestido de Despoina también desde esta perspectiva. Encontrar algún significado político-ideológico en la iconografía de la indumentaria divina podría, quizás, conducir a encuadrar la costosa dedicatoria del grupo escultórico damofonteo en el santuario de Licosura (y, muy

6. En total se distinguen unas 15 figuras, que permiten reconocer al menos cuatro o cinco tipos de cabezas de animales (caballo/potro, asno, cerdo, oveja y, quizás, zorro) y tres tipos de instrumentos musicales (doble flauta, cítara, triángulo). Del mismo santuario proceden unas 140 figurillas de terracota con cabeza de animal, de época romana. La investigación moderna suele considerar a las figuras de Licosura representadas con cabeza de animal como seres humanos enmascarados (sacerdotes y/o devotos/iniciados: Jost, 2003, en especial pp. 156-166, con referencias a la bibliografía anterior; sacerdotes/ devotos/iniciados y/o technitai dionisíacos: Tsiolis, 2018, pp. 176-180); de parecer contrario es E. Aston, que sugiere reconocer en ellas seres híbridos (Aston, 2011, pp. 235-252; 300-301).

7. Véanse, entre otros, Dickins, 1906-1907, pp. 373-374; cf. 384-389); Kourouniotis, 1911; Wace, 1934, pp. 107-111; Stiglitz, 1967, p. 38 (la iconografía del vestido simbolizaría la universalidad del poder divino, que abarca los dominios celeste y marino); Marcadé y Lévy, 1972, pp. 967-1004 (en especial, pp. 979988); Jost, 1985, p. 334 (rechaza la idea que la iconografía del vestido - demasiado rutinaria - tuviese valor simbólico); ead, 2003, pp. 143-168, en especial pp. 156-166, con referencias a la bibliografía anterior; Moreno, 1994, pp. 511-512; Morizot, 2008, pp. 203-207. Sobre el arte del bordado en la tradición griega, Wace, 1948; sobre los métodos de la tejeduría griega, Barber, 1992; sobre la problemática terminológica del arte del bordado: Patera, 2012; Vickers, 1999, con referencias al vestido de Despoina, desafortunadas desde el punto de vista cronológico ("part of what was probably a roman period work"), en pp. 24-25; en general sobre la indumentaria en Grecia, véase, entre otros, Pekridou-Gorecki, 1989.

ARYS, 17, 2019 [65-83] ISSN 1575-166X 
probablemente, una radical reforma - sino nueva construcción - del templo) ${ }^{8}$ en algún contexto histórico particularmente favorable para ese tipo de iniciativas en la región. Contemplando la decoración del manto d Despoina desde la perspectiva del gran desembolso que, sin duda, ha significado para quien ha comisionado la revitalización del santuario en el siglo II a.C., e incluso tomando en consideración el lugar donde se invierte dicho esfuerzo económico (un santuario, periférico y liminal, muy alejado del mar), cabría vislumbrar detrás del proyecto intenciones de exaltación y de promoción propagandística de alguna realidad no estrictamente religiosa. Dejando de lado el friso con las figuras de los danzantes, probable alusión a alguno de los drómena o performances llevados a cabo en el santuario, que más ha atraído la atención de la investigación moderna, el análisis del resto la iconografía de la prenda, aparentemente rutinaria desde el punto de vista del repertorio decorativo (águilas y rayos de Zeus, thiasos marino, ramas de olivo - o de laurel - y

8. A la luz de la inscripción de Mesene SEG 41,332, Petros Themelis ha datado la actividad de Damofón entre el último cuarto del siglo III y el año 182 a.C., a partir de criterios históricos e históriconumismáticos (Themelis, 1993). Con anterioridad al hallazgo y publicación de la inscripción, prevalecían dataciones sobre todo en el siglo II a.C.: Dickins, 1905-1906; Thallon, 1906; Dinsmoor, 1941. Moreno, 1994, pp. 506 y 507-514 (especialmente, nota 814), data del grupo de Despoina en el período 183-168 a.C., atribuyendo la monumentalización del santuario licurasio a la iniciativa de Licortas, responsable de la capitulación de Mesene. Junto a la búsqueda de prestigio personal por parte de este strategós de la Liga aquea, Paolo Moreno recuerda la necesidad de restauración de los daños provocados en distintos santuarios de Peloponeso por el terremoto del 183 a.C. (en p. 507), aunque no existen alusiones expresas de las fuentes al santuario de Licosura. Una parte más reducida de la investigación optaba, sin embargo, por fechas más altas, del siglo III a.C. o anteriores (e.g. Jost, 1985, pp. 174-176), tendencia que cuenta aún con algunos defensores (Marcadé, 2008, p. 116 - "sinon au IVe siècle ..., du moins à la première moitié du IIIe siècle" -; cf. la propuesta de datación del templo en el primer tercio del siglo III a.C. en Billot, 2008, passim; p. 172). La hipótesis cronológica de Themelis, sin embargo, ha sido respaldada por gran parte de la investigación (e.g. Torelli, 1998; cf. Ridgway, 2000, pp. 237-240; Sève, 2008). No obstante, existe una creciente tendencia, que, desde distintos puntos de vista y con argumentos diferentes en cada caso, sugiere rebajar de pocas o varias décadas la cronología del escultor, situándola a lo largo de la primera mitad del siglo II a.C. (incluso en el segundo cuarto): además de Moreno, 1994, pp. 506 y 507-514, véanse, e.g., Tsiolis, 2002, que sugiere el período 174-168 a.C. o un marco de tiempo ligeramente ampliado, para el trabajo de Damofón a Megalópolis; Melfi, 2016, especialmente pp. 99-100 y 104-105, que propone una fecha para la actividad del escultor en algunas ciudades del Mar Jónico posterior al año 160 a.C. Con todo y para evitar confusiones, aunque se acepte cierta monumentalización del santuario coincidiendo con la fundación de Megalópolis (post 370 a.C.) o en las dos o tres décadas inmediatamente posteriores, no es sostenible una cronología igualmente alta para el grupo escultórico damofonteo, pues faltan argumentos aceptables - arqueológicos, históricos o artísticos - que apunten en esta dirección. 
de mirto, Nikai portadoras de "incensarios") podrían encontrar una lectura más precisa fuera del ámbito estrictamente religioso o meramente artístico. ${ }^{9}$

No han faltado propuestas hasta la fecha, orientadas a contextualizar la revitalización (o el consciente intento de dinamización) del santuario de Licosura en algún ambiente político concreto, reconociendo en esta acción un fondo ideológico de prolongaciones propagandísticas. Recientemente, Alaya Palamidis ha vislumbrado intereses político-ideológicos megalopolitanos detrás de la promoción (o, incluso "creación") del santuario licurasio, orientados a la consolidación del propio papel de líder regional, al que aspiraba Megalópolis desde su fundación en la década de los años sesenta del siglo IV a.C. (promoción que pudo haberse consumado en distintas etapas a lo largo de los siglos III y II a.C.). ${ }^{10}$ Con anterioridad, Th. Mavrogiannis había sugerido una posible vinculación de la monumentalización del santuario y de la obra de Damofón con acontecimientos político-bélicos y diplomáticos del período de la actividad de T.Q. Flaminino en Grecia, en la década de los noventa del siglo II a.C. ${ }^{11}$ En su opinión, el proyecto pudo haber sido promocionado por la Liga Aquea (o incluso por el propio T.Q. Flaminino) y financiado con botín de guerra, ya que otras vías de financiación de un proyecto de estas características resultarían inviables (a excepción, quizás de alguna donación extranjera).

Precisamente este contexto de las primeras décadas del siglo II a.C., en el que la mayoría de la investigación sitúa la actividad del escultor Damofón, resulta particularmente propicio para la promoción del santuario de Licosura. Aunque figura como ciudad autónoma en ese momento, ${ }^{12}$ Licosura se encuentra sin duda a la sombra se Megalópolis, ciudad que ha de ser entendida como el verdadero promotor del proyecto. Como es sabido, durante las dos primeras décadas del siglo II a.C., Megalópolis, encabezada por Filopemen y otras personalidades de su círculo, ostenta un papel protagonista en el seno de la Liga Aquea. En el contexto histórico entre finales del siglo III a.C. y primeras décadas del siguiente, no han sido muchas las ocasiones en las que Licosura pudo haberse beneficiado de un botín de guerra significativo: las tres más destacadas victorias obtenidas por la Liga Aquea, guiada y controlada por la élite megalopolitana cercana a Filopemen, han sido la del año

9. Véase, e.g., Moggi y Osanna, 2003, p. 471 (comentario a Paus., VIII 37, 3-4: "La complessa decorazione alludeva evidentemente tanto alle dinamiche rituali del santuario, quanto ai miti e alle associazioni cultuali connesse...").

10. Palamidis, 2018, en especial pp. 143-145; sobre política y religión en Arcadia, véase, brevemente, Jost, 2008b.

11. Mavrogiannis, 2003, pp. 121-136; id., 2004, en especial, pp. 17-18.

12. Sobre la cuestión, véanse, Tsiolis, 2002, pp. 22-23; Palamidis, 2018, en especial pp. 131-132. 
195-194 a.C., en el marco de la Guerra de los romanos de T.Q. Flaminino, junto con aqueos, pergamenos y rodios contra Nabis de Esparta (captura del puerto de Gythion y, un año después, capitulación de Esparta); la del 193 a.C, cuando el propio Filopemen encabezó sin fortuna la flota aquea en la batalla naval de Gythion, logrando sin embargo devastar los alrededores de Esparta; y, la del año 182 a.C., cuando, tras la ejecución de Filopemen, cautivo en Mesene, esta ciudad, patria del escultor Damofón, fue capturada por parte de Licortas de Megalópolis, estratego de la Liga aquea y padre del historiador Polibio.

La presencia de temática marina, caso del friso con el thiasos marino ${ }^{13} \mathrm{del}$ vestido de Despoina, así como las cuatro figuras de Tritonisas que rodeaban el grupo cultual, si bien encuentra explicación satisfactoria en la tradición que hacía de Poseidón el padre de Despoina, deja abierta la posibilidad de una interpretación diferente o complementaria, en clave triunfalista, alusiva quizás a hechos marinos reales. Igualmente las dos figuras de Nikai, que dominan la franja decorada más ancha del vestido, a pesar de constituir una temática relativamente habitual en contexto religioso, también podrían ser alusivas a celebraciones de victorias reales. En el friso las dos Nikai se mueven de izquierda hacia derecha, elevando con las manos unos objetos tradicionalmente interpretados como thymiateria/incensarios (o, quizás bomiskoi portátiles), específicamente usados en actos sacrificiales. ${ }^{14}$ En esta representación se puede reconocer una alusión al sacrificio, que se prestara a una lectura en clave ideológica e triunfalista, más allá de sus connotaciones estrictamente religiosas. En el mundo griego (y romano) las Nikai-Victorias se asocian con frecuencia con el sacrificio, habitualmente del toro, en contextos cívico-reli-

13. Véase, entre otros, Lattimore, 1976.

14. Sobre los thymiateria, en general, Wigand, 1912, en especial, tav. III, núms. 82-96); Zaccagnino, 1998, con tipología (en especial, véase el tipo E, de fuste sobre base toncocónica, pp. 72-73) e iconografía de los thymiateria asociados a las Nikai (pp. 87-88), además de debate terminológico (en relación con los bomiskoi, pp. 72-73); Simon, Haiganuch y Milanezi, 2004. En la tradición cultual latina objetos similares aparecen con frecuencia en la iconografía vinculada a los sacrificios. Una reciente interpretación de V. Gasparini de estos objetos como altaria, corroborada y ampliada posteriormente por F.G. Cavallero, parece encontrar refrendo también en algunos textos literarios. Sobre la cuestión de los altaria, véanse Gasparini, 2008, pp. 39-47; Cavallero, 2017, con citas de fuentes en p. 590 entre las que cabe destacar a Varrón (ap. Serv., Buc. V 66): Varro diis superis altaria, terrestribus aras, inferis focos dicari adfirmat y Festo (Paul. Fest. 27L): Altaria ab altitudine sunt dicta, quod antiqui diis superis in aedificiis a terra exaltatis sacra faciebant; diis terrestribus in terra, diis infernalibus in effossa terra; Cavallero, 2018. Agradezco a Valentino Gasparini sus útiles comentarios y sus pertinentes indicaciones bibliográficas sobre la posible interpretación de los objetos portados por las Nikai del manto de Despoina en clave análoga a la de los objetos similares de la liturgia sacrificial del mundo romano.

ARYS, 17, 2019 [65-83] ISSN 1575-166X 
giosos de afirmación de la victoria, de alta carga ideológica. Así parecen indicarlo representaciones como las de las Nikai de la balaustrada del Templo de Atenea Nike Apteros, de la Acrópolis ateniense, las distintas Victorias romanas de las placas tipo Campana o las de los relieves del Foro de Trajano en Roma. ${ }^{15}$

El segundo caso arcadio de indumentaria divina que me propongo a discutir concierne al peplos ofrendado a Atenea Alea de Tegea, por parte de una devota chipriota, de nombre Laodice. Pausanias, en los capítulos introductorios de sus Arkadiká y tras relatar la participación de los arcadios en la Guerra de Troya bajo el mando del rey de Tegea Agapenor, así como la posterior fundación de Pafos en Chipre por iniciativa de éste, ${ }^{16}$ recoge una noticia sobre un contacto posterior entre Pafos y Tegea, materializado en forma de ofrendas religiosas por parte de una tal Laodice, a la que el propio Periegeta, seguramente siguiendo la información que le proporcionaron sus guías locales, señala como descendiente del rey Agapenor: "Posteriormente, Laodice, descendiente de Agapenor, envió a Tegea una túnica (peplos) como ofrenda para Atenea Alea. La inscripción en la ofrenda indicaba también la estirpe de Laodice: Esta es la túnica de Laodice; ella lo dedicó a su Atenea, en su vasta tierra natal, desde Chipre, la Divina". ${ }^{17}$ En otro pasaje de su relato, tratando de la descripción de Tegea, Pausanias vuelve a referirse a Laodice, esta vez para recordar que fue ella quien dedicó a la ciudad el Templo de Afrodita Paphia: “También hay en Tegea un templo de Deméter y Core a las que denominan Carpóforas y cerca (un templo) de Afrodita de Pafos. A ésa la dedicó/fundó Laodice, descendiente, como ya he dicho, de Agapenor, quien llevó a los arcadios a Troya, y fue en Pafos donde ella moraba". ${ }^{18}$

Varios autores se han planteado la cuestión de la identidad de Laodice. En el pasado, y a pesar de los numerosos indicios en contra, algunos la han considerado como hija mítica de Agapenor, interpretando la narrativa pausaniana como un invento mitológico tegeata. Sin embargo, en el año 1987, J. Roy ha demostrado con criterios históricos, histórico-literarios y filológicos que la datación que permite el epigrama es necesariamente tardía y, por tanto, la actividad de Laodice ha de ser

15. LIMC, 6.1, Nike, 850-904; cfr. LIMC, 8.2, Victoria, 237-269.

16. Sobre el homérico Agapenor y los estudios relativos a su migración a Chipre véanse Gjerstad, 1944 y, más recientemente, Scheer, 2018, especialmente pp. 72-78.

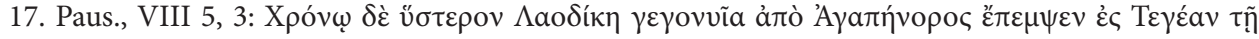

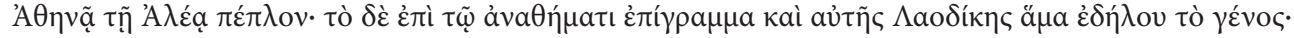

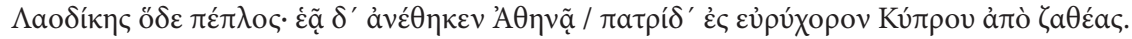

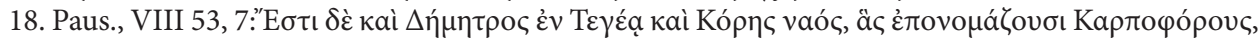

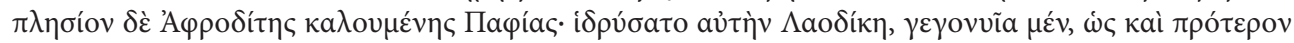

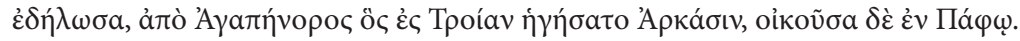

ARYS, 17, 2019 [65-83] ISSN 1575-166X 
enmarcada en el período helenístico. ${ }^{19}$ Este investigador señalaba, además, que el epigrama en sí no hace referencia alguna a una relación entre Agapenor, Pafos y Laodice, sino que tal nexo constituye una aportación pausaniana. En consecuencia, la ofrenda votiva del peplos, así como la dedicatoria realizada en el templo de Afrodita Paphia de Tegea (sino el propio templo y la institución del culto), ${ }^{20}$ han de entenderse como auténticas, realizadas por una persona llamada Laodice, que había existido realmente. Parece, así, lícito pensar, que Laodice fuese una acomodada emigrante tegeata a Chipre (o descendiente de emigrantes arcadios), que no se había olvidado de Tegea, fuera su tierra natal o la de alguno de sus antepasados cercanos. Las alusiones a los lazos con el mito de Agapenor, en tal caso, se habrían establecido, por derivación, por Pausanias mismo o por los propios tegeatas. ${ }^{21}$

No se puede determinar si Pausanias vio efectivamente el peplos de Laodice en Tegea, pero supo de una inscripción relacionada con la ofrenda (¿grabada o escrita en alguna tabla o placa junto a la pieza?; ¿ bordada sobre el tejido?). Incluso si suponemos que, debido a la naturaleza perecedera del textil, el peplos ya no existiera en sus tiempos, tal vez el Periegeta fuese informado por sus guías, que guardasen memoria de ello o que conociesen la ofrenda a través de eventuales registros con los inventarios de los ex-voto. Al parecer, la tradición de Laodice de Pafos se le antojó bastante significativa a Pausanias como para mencionarla dos veces. Quizás esto ponga de manifiesto el afán de los sacerdotes y guías locales en resaltar la antigua relación de Tegea con Homero y Chipre aún en época imperial, o el entusiasmo del propio Pausanias al encontrar "pruebas" palpables de la "veracidad" del epos.

En el estado actual de la investigación, no se conoce directamente ninguna persona real con el nombre Laodice en Pafos. Es sabido que este nombre de persona gozaba de gran prestigio para los griegos, especialmente el época helenística. El nombre, conocido ya en la Macedonia de Filipo II, era muy frecuente entre las mujeres de la casa real seléucida entre los siglos III y II a.C., pero también se había popularizado entre otras dinastías (Ponto, Capadocia, Bactria, Comagene). También aparece con

19. Roy, 1987.

20. La interpretación del texto pausaniano induce a J. Roy (ibid., pp. 194-195) a descartar la posibilidad de que Laodice construyera el templo y fundara el culto de Afrodite Paphia y piensa que su dedicatoria consistiera solamente en una imagen de la diosa.

21. Sobre esta tradición de la agapenorida Laodice, que vincula a Chipre con Tegea, véanse, entre otros: Pirenne-Delforge, 1994, en especial, pp. 327-330; Zizza, 2006, con discusión de la inscripción mencionada por Pausanias en pp. 317-325; comentario a Paus., VIII 5, 3 en Moggi y Osanna, 2003, pp. 313-314 (también el comentario a Paus., VIII 53, 7, sobre la localización del templo de Afrodita Paphia afia en Tegea, en p. 528); y, especialmente, la reciente aportación de Tanja Scheer (Scheer, 2018). 
cierta frecuencia en contextos mitológico-literarios (hija de Priamo y Hecuba; hija de Agamenón y Clitemnestra), destacando, sin duda, la referencia de Apollodoro a una Laodice, hija de (¿un?) Ciniras y esposa del arcadio Élato. Se suele pensar que, en este caso, se tratase de una princesa mítica chipriota, aunque Apolodoro no la incluyese explícitamente entre las hijas del rey Ciniras de Chipre, mencionadas en otro pasaje. ${ }^{22}$ Con todo, ninguna de estas figuras mitológicas de nombre Laodice guarda relación con la prole chipriota del tegeata Agapenor. Sin embargo, la vinculación entre Laodice, el rey Ciniras y la Arcadia (Élato) que efectúa Apolodoro genera cierta perplejidad, si se tiene en cuenta la geografía (Pafos) y la competencia entre ciníridas y agapenóridas en torno al antiguo santuario de Afrodite en este enclave chipriota. ${ }^{23}$ Sobre esa cuestión volveré más adelante.

Se ha observado que las ofrendas de Laodice a Tegea, indicativas de su holgada posición económica, la deben situar en las esferas más acomodadas de la sociedad. Difícilmente se podría pensar, en consecuencia, a una mujer de recursos económicos moderados, como eventualmente podrían ser, por ejemplo, las esposas o parientes de mercenarios emigrantes a Chipre. ${ }^{24}$ Aún así, no resulta fácil encuadrar a Laodice en algún contexto familiar concreto. Teniendo en cuenta el corpus documental disponible, que vincula de alguna manera a Chipre con Tegea, apenas existen vías que permitan una aproximación a la figura de Laodice y ayuden a percibir el contenido ideológico de sus ofrendas a Tegea. Una de ellas podría especularse en ámbito seléucida, donde abunda el nombre Laodice. Sin embargo, el reino de Siria poco tenía que ver con Chipre, estando la isla controlada por los ptolomeos de Egipto desde principios del siglo III a.C. Sin embargo, en una ocasión, los sirios se hicieron, fugazmente, con el control de Chipre: Antíoco IV Epífanes, en el año 168 a.C. logró arrebatar Chipre a los ptolomeos, instaurando momentáneamente su propio régimen. Desconocemos si hubo maniobras diplomáticas en las que pudiese haberse visto implicada su influyente esposa y reina de Siria, Laodice IV. La Liga Aquea, de la que Tegea era miembro, aún jugaba por estas fechas sus últimas cartas en el tablero político internacional, siendo un referente para las maniobras diplomáticas de varias potencias extranjeras. Durante las primeras décadas del siglo II a.C., los ptolomeos negociaban con la

22. Apollod., Bibl. III 9, 1: Laodice, hija de Ciniras, se casa con el arcadio Élato; en III 14, 3 entre las tres hijas del rey de Chipre Ciniras (Orsedice, Laogore y Bresia), no se menciona ninguna Laodice.

23. En Pafos prevaleció durante la época clásica la figura del rey mítico prehelénico Ciniras, héroe epónimo de la casa real de Pafos y figura de la que se hacía descendiente la familia sacerdotal de Afrodita (los ciníridas): véase, Scheer, 2018, especialmente pp. 77-78.

24. Ibid. p. 86 . 
Liga; ${ }^{25}$ Pérgamo firmaba con Tegea tratados basados en la supuesta syngeneia entre ambas ciudades; ${ }^{26}$ y el propio Antíoco IV, entre 175 y 174 a.C., de vuelta a Siria desde Roma y aún antes de su coronación, había realizado importantes donaciones a varias ciudades de la Liga con el propósito de ganar sus simpatías. Por medio de donaciones a ciudades representativas del mundo griego en general y de la Liga Aquea, en particular, Antíoco intentaba tejer una red diplomática que le garantizara el favor de estas ciudades en el futuro. Entre las beneficiarias de la donaciones de Antíoco había también dos ciudades arcadias, ambas miembros de la Liga Aquea: Megalópolis, que todavía ostentaba un papel protagonista en el seno de la Liga y que gracias a Antíoco pudo reconstruir parte de su muralla; y, precisamente Tegea, en la que el sirio mandó construir un teatro de mármol. ${ }^{27}$ Con todo, no tenemos noticia de que Antíoco IV emprendiera acción diplomática alguna entre los miembros de la Liga Aquea con el fin de legitimar y consolidar la ocupación de Chipre. Tampoco se conocen vínculos de syngeneia entre la reina Laodice IV y Tegea, que acaso permitiría avanzar la investigación en esta dirección, si bien la maquinaria propagandística seléucida bien podría quizás haber elaborado cualquier tipo de genealogías inventadas que le facilitaran sus aspiraciones políticas. Pero, además, en estos momentos la Liga Aquea, y con ella las ciudades arcadias como Megalópolis y Tegea, se encontraban ante el desenlace final del pulso entre Perseo y Roma, en una posición delicada y poco propicia para iniciativas diplomáticas con potencias extranjeras.

Sin embargo, cabe explorar otro filón, que podría encajar mejor con la donación de Laodice a las divinidades tegeatas. Pausanias, al vincular a Laodice con el linaje de Agapenor, podría tener en mente una conexión con los agapenóridas helenísticos de Pafos. Esta familia está documentada epigráficamente en el antiguo santuario de Pafos, en torno al 160-150 a.C. ${ }^{28}$ Sus miembros femeninos ostentan nombres de abolengo regio (Echetime, Euagoratis) y los varones retoman el antiguo nombre del rey mítico tegeata. Aunque no se conoce ninguna mujer de nombre Laodice en esta familia aristocrática, era costumbre típica de sus miembros femeninos, así como entre las mujeres de otras familias de alta posición social de la (Nea) Pafos helenística, la financiación de costosas ofrendas en santuarios: precisamente Echetime, hija de Agapenor de Pafos, dedicó las estatuas de sus hijos en el santuario de Afrodita. ${ }^{29}$

25. Polyb., XXIV 6.

26. IvP 156.

27. Liv., XLI 20, 4: Megalopolitanis in Arcadia murum se circumdaturum urbi est pollicitus maioremque partem pecuniae dedit; Tegeae theatrum magnificum e marmore facere instituit.

28. Sobre esta familia, Scheer, 2018, en especial, pp. 78-79, con bibliografía anterior.

29. Sobre la diosa Afrodita en Chipre, Pirenne-Delforge, 1994, pp. 309-369. 
Ahora bien, cabe recordar que durante un largo período, entre los años 197 y 181 a.C., reinando en Egipto Ptolomeo V, Epífanes, la isla de Chipre había sido gobernada por un arcadio, Ptolomeo de Megalópolis, strategós de los reyes de Egipto. Sabemos que la hija de este arcadio desempeñó, asimismo, un alto cargo sacerdotal en el marco del culto dinástico del rey Ptolomeo V Epífanes en Chipre, del que su padre, el gobernador, ejercía de archiereus, con competencias sobre toda la isla. Quizás se podría identificar a este gobernador arcadio de Chipre con el historiador megalopolitano homónimo, que escribió una historia de Ptolomeo IV Filopator y, además, mostró gran interés por el pasado mitológico de Chipre, escribiendo a propósito de las tumbas de los ciníridas, descendientes del mítico rey chipriota Ciniras, ${ }^{30}$ en el santuario de Afrodita Paphia en Pafos. Cabría pensar que, si el historiador Ptolomeo de Megalópolis haya visitado las tumbas de los ciníridas y haya redactado un relato, también podría haberse interesado, como arcadio, por las tumbas de los agapenóridas, al margen de si se le hubiese enseñado o no una eventual tumba de Agapenor. ${ }^{31}$ Esta idea es aún más probable si se tiene en cuenta que un epigrama funerario recogido en el Peplos pseudo-aristotélico indica que la tumba de Agapenor había sido localizada en Pafos, aún sin especificar cuándo. ${ }^{32} \mathrm{La}$ vinculación del santuario de Pafos con Agapenor y los arcadios generaba sin duda una circunstancia especial, que podría resultar de utilidad tanto para el strategós arcadio de Chipre, representante máximo del rey Ptolomeo V Epífanes en la isla (si se identifica con el historiador), como por el clero y la élite de Pafos. Durante el gobierno de los Ptolomeos el templo de Afrodita en Pafos fue el lugar donde las familias prominentes cultivaran su imagen pública, dedicando estatuas de sus hijos a la diosa. Tras el derrumbe de la dinastía real chipriota, este santuario también servía de espacio para el encuentro entre las élites locales y los gobernadores ptolemaicos - strategoi -, a través de estatuas y dedicaciones honoríficas. ${ }^{33}$

Es plausible suponer, que la presencia de un gobernador originario de Arcadia haya acelerado el auge de la tradición de Agapenor entre las élites de Pafos. ${ }^{34}$ La rein-

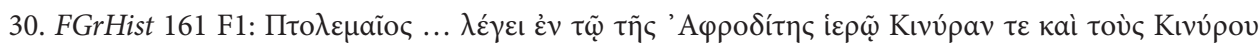

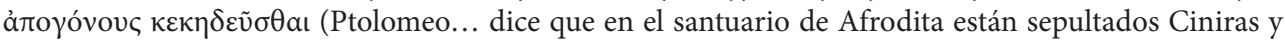
los descendientes de Ciniras).

31. Scheer, 2018, pp. 82-86, con citación de fuentes y bibliografía anterior. Ciniras, aun teniendo una relación privilegiada con Afrodita ya en la literatura de época clásica, emerge como fundador de Pafos tan sólo en época helenística, ya que es mencionado como tal por primera vez en Apolodoro (Apollod., Bibl. III 14, 3).

32. Anth. lyrica, 30 Hiller-Crusius, p. 358 , n. 30.

33. Véase, Mavrogiannis, 2016.

34. Scheer, 2018, p. 83.

ARYS, 17, 2019 [65-83] ISSN 1575-166X 
vención de lazos míticos comunes con los representantes del nuevo poder político podría resultar beneficioso también para los Ptolomeos, en su intento de integrar la isla en el reino. En este contexto podrían haber surgido varias mitologías fundacionales en toda la isla, que potenciaran las tradiciones mitológicas hasta que éstas, puestas al servicio del poder político, adquiriesen "fuerza histórica" ${ }^{35}$ La tradición de Agapenor, más o menos viva en Chipre, en algún momento de época hellenística, que podría coincidir con las primeras décadas del siglo II a.C., se revitaliza y regresa a Tegea, probablemente convertida en herramienta política y diplomática. De hecho, como indica Tanja Scheer, tras el final de los reinados chipriotas, parece que los representantes de la realeza se integraron en los nuevos poderes por medio de "redes de parentesco", que los acercaban a sus nuevos y cambiantes interlocutores-patrones. En consecuencia, no sería de extrañar que los chipriotas se esforzaran para forjar conexiones con Arcadia, patria del máximo mandatario de su isla, Ptolomeo de Megalópolis. Sin embargo, aunque las ofrendas votivas enviadas a Tegea por una, no mejor identificada, supuesta descendiente de Agapenor encajen bien en un contexto de diplomacia de la syngeneia y aún existiendo el paradigma pergameno-tegeata, parece excesivamente arriesgado suponer que hubiese habido misiones diplomáticas chipriotas a Tegea, reivindicando los antiguos lazos de parentesco (quizás buscando confirmación de la asylia del templo de Afrodita o la obtención de isopoliteia). Aún así, la tradición del peplos de Laodice en Tegea, todavía viva en el siglo II d.C., servía de intermediario capaz de convertir el mito en "historia", formando parte, en palabras de en palabras de Tanja Scheer, del "proceso emergente de creación de redes míticas, casi históricas, y redes históricas de imaginación colectiva”.

35. Ibid. 


\section{Bibliografía}

Aston, E. (2011). Mixanthropoi. Animal-human hybrid deities in greek religion, Lieja: Presses Universitaires de Liège.

Audley-Miller, L. y Dignas, B. (eds.) (2018). Wandering Myths. Transcultural Uses of Myth in the Ancient World, Berlín: De Gruyter.

Balty, J. (ed.) (2004). Thesaurus Cultus et Rituum Antiquorum (ThesCRA). Processions, sacrifices, libations, fumigations, dedications, Los Ángeles: Getty Publications.

Barber, E. (1992). The Peplos of Athena. En Neils, 1992, pp. 103-107.

Billot, M.F. (2008). Le Temple de Despoina. Ktema, 33, pp. 135-180.

Bricault, L. (ed.) (2008). Bibliotheca Isiaca, I, Burdeos: Ausonius.

Capecchi, G. et alii (eds.) (1998). In Memoria di Enrico Paribeni. Roma: Giorgio Bretschneider.

Cavallero, F.G. (2017). Arae e altaria: una possibile differenza morfologica. $A r c h C l, 68$, pp. 589-408.

Cavallero, F.G. (2018). Arae sacrae. Tipi, nomi, atti, funzioni e rappresentazioni degli altari romani, BULLCOM Suppl. 25, Roma: L'Erma di Bretschneider.

Cosmopoulos, M. (ed.) (2003). Greek Mysteries. The Archaeology of Ancient Greek Secret Cults. Londres y Nueva York: Psychology Press.

Dickins, G. (1905-1906). Damophon of Messene I: His Date. ABSA, 12, pp. 109-136.

Dickins, G. (1906-1907). Damophon of Messene II. ABSA, 13, pp. 357-404.

Dinsmoor, W.B. (1941). An archaeological earthquake at Olympia. AJA, 45, pp. 399-427.

Gasparini, V. (2008). Altaria o candelabra? Aspetti materiali del culto di Iside illuminati dalla testimonianza di Apuleio. En Bricault, 2008, pp. 39-47.

Gjerstad, E. (1944). The colonization of Cyprus in Greek legend. OA, 3, pp. 107-123.

Grandjean, C. y Nicolet-Pierre, H. (2008). Le décret de Lykosoura en l' honneur de Damophon et la circulation monétaire dans le Pélopponèse aus IIIe-IIe siècles avant notre ère. Ktema, 33, pp.129-134.

Jost, M. (1985). Sanctuaires et cultes d'Arcadie, París: Vrin.

Jost, M. (2003). Mystery cults in Arcadia. En Cosmopoulos, 2003, pp. 143-168.

Jost, M. (2008a). La vie religieuse à Lykosoura, Ktema, 33, 2008, pp. 93-110.

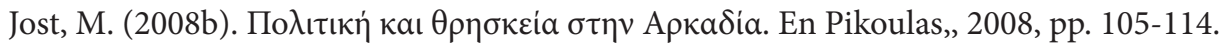

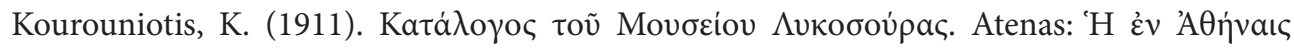

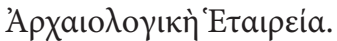

Lattimore, S. (1976). The Marine Thiasos in Greek Sculpture, Los Ángeles: The University of California.

Marcadé, J. (2008). À propos du groupe cultuel de Lykosoura. Ktema, 33, pp. 111-116.

Marcadé, J. y Lévy, E. (1972). Au musée de Lycosoura. BCH, 96.2, pp. 967-1004.

Mavrogiannis, Th. (2003). Aeneas und Euander: mythische Vergangenheit und Politik im Rom vom 6. Jh. v. Chr. bis zur Zeit des Augustus. Nápoles: Edizioni Scientifiche Italiane. 
Mavrogiannis, Th. (2004). Evandro sul Palatino. La canonizzazione della tradizione arcade di Roma nel contesto politico della storia del II sec. a.C. Atene e Roma, 2004.1, pp. 6-20.

Mavrogiannis, Th. (2016). The Mausoleum of Ptolemy Eupator and the «Tombs of the Kings» at Nea Paphos in the Light of the Portraiture of the Ptolemaic Strategoi of Cyprus From Voni-Kythrea. Ostraka, 25, pp. 119-162.

Melfi, M. (2016). Damophon of Messene in the Ionian Coast of Greece: Making, Re-making, and Updating Cult Statues in the Second Century BC. En Melfi y Bobou, 2016, pp. 82105.

Melfi, M. y Bobou, O. (eds.) (2016). Hellenistic Sanctuaries. Between Greece and Rome. Oxford: Oxford University Press.

Moggi, M. y Osanna, M. (2003). Pausania, Guida della Grecia, libro VIII, L’Arcadia. Milán: Fondazione Lorenzo Valla.

Moreno, P. (1994). Scultura ellenistica, 1-2. Roma: Istituto Poligrafico dello Stato.

Morizot, Y. (2008). La draperie de Despoina. Ktema, 33, pp. 201-209.

Neils, J. (ed.) (1992). Goddess and Polis. The Panathenaic Festival in Ancient Athens. Hanover N.H. y Princeton N.J.: Princeton University Press.

Palamidis, A. (2018). The Sanctuary of Despoina at Lykosoura: A Megalopolitan Creation?. En Tausend, 2018, pp. 127-151.

Patera, M. (2012). Problèmes de la terminologie grecque du vêtement : recherche sur la broderie. En Tzachili y Zimi, 2012, pp. 117-130.

Pekridou-Gorecki, A. (1989). Mode im antiken Griechenland. Textile Fertigung und Kleidung. Munich: C.H. Beck.

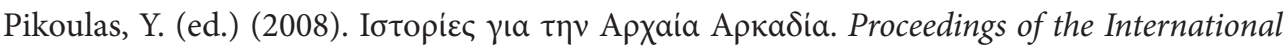

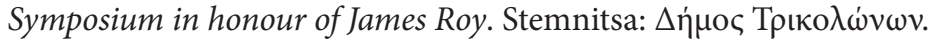

Pirenne-Delforge, V. (1994). L’Aphrodite grecque, Kernos Supplément IV, Atenas y Lieja: Presses universitaires de Liège.

Ridgway, B. (2000). Hellenistic Sculpture II. The Styles of ca. 200-100 B.C. Wisconsin: University of Wisconsin Press.

Roy, J. (1987). Paus. 8.5.2-3 and 8.53.7. Laodike, Descendant of Agapenor, Tegea and Cyprus. $A C, 56$, pp. $192-200$.

Scheer, T. (2018). Myth, Memory and the Past. Wandering Heroes between Arcadia and Cyprus. En Audley-Miller y Dignas, 2018, pp. 71-91.

Sève, M. (2008). Le dossier épigraphique du sculpteur Damophon de Messène. Ktema, 33, pp. 117-128.

Simon, E., Haiganuch, S. y Milanezi, S. (2004). 2.c. Rauchopfer. En Balty, 2004, pp. 255-268.

Stiglitz, R. (1967). Die Grossen Gottinnen Arkadiens. Viena: Österreichischen Archäologischen Institut.

Tausend, K. (ed.) (2018). Arkadien im Altertum. Geschichte und Kultur einer antiken Gebirgslandschaft. Gratz: UniPress Graz.

Thallon, I.C. (1906). The Date of Damophon of Messene. AJA, 10.3, pp. 302-329. 
Themelis, P. (1993). Damophon von Mesene: sein Werk im Lichte der neuen Ausgrabungen. AntK, 36, pp. 24-50.

Torelli, M. (1998). L’Asklepieion di Messene, lo scultore Damofonte e Pausania. En Capecchi et alii, 1998, pp. 466-483.

Tsiolis, V. (2002). Damofón, Sosígenes y la introducción de los misterios eleusinos en Megalópolis. Eutopia, 2.1, pp. 7-32.

Tsiolis, V. (2018). Arkadian religious matters: further considerations on the teleté of the Great Goddesses at Megalopolis and on the koreiteai at Despoina's Sanctuary at Lykosura. With an appendix on the so called Sanctuary of Zeus Homarios and Hestia at Megalopolis. En Tausend, 2018, pp. 175-196.

Tzachili, I. y Zimi, E. (eds.) (2012). Textiles and Dress in Greece and the Roman East: A Technological and Social Approach. Atenas: Ta Pragmata.

Vickers, M. (1999). Images on textiles: The weave of fifth-century Athenian art and society. Konstanza: Universitatsverlag Konstanz.

Wace, A.J.B. (1934). The Veil of Despoina. AJA, 38.1, pp. 107-111.

Wace, A.J.B. (1948). Weaving or Embroidery?. AJA, 52.1, pp. 51-55.

Wigand, K. (1912). Thymiateria: Inaugural-Dissertation. BJ, 122, pp. 1-97.

Zaccagnino, C. (1998). Il thymiaterion nel mondo greco: analisi delle fonti, tipologia. Roma: L'Erma di Bretschneider.

Zizza, C. (2006). Le iscrizione nella Periegesi di Pausania. Commento ai testi epigrafici. Pisa: Edizioni ETS. 